\title{
Erratum: Study of GaN thin layers subjected to high-temperature rapid thermal annealing [Semiconductors 32, 1048-1053 (October 1998)]
}

N. I. Katsavets

Private Joint-Stock Company “'Semiconductor Devices,'” 192281 St. Petersburg, Russia

G. M. Laws, I. Harrison, E. C. Larkins, and T. M. Benson

Department of Electrical and Electronic Engineering, University of Nottingham, Nottingham NG7 2RD,

England

T. S. Cheng and C. T. Foxon

Department of Physics, University of Nottingham, Notthingham NG7 2RD, England

Fiz. Tekh. Poluprovodn. 33, 120 (January 1999)

[S1063-7826(99)02701-5]

On page 1048, the first sentence of Sec. 2 should read "RHTA was performed in a quartz reactor at $1000{ }^{\circ} \mathrm{C}$ for $30 \mathrm{~s}$ in a stream of $\mathrm{N}_{2}$ or Ar."

Translated by M. E. Alferieff 